\title{
MANIFESTAÇÕES CLÍNICAS DO LÚPUS ERITEMATOSO SISTÊMICO: ABORDAGEM DIAGNÓSTICA E TERAPÊUTICA NA SALA DE URGÊNCIA
}

\author{
CLINICAL MANIFESTATIONS OF SYSTEMIC LUPUS ERYTHEMATOSUS: \\ DIAGNOSTIC AND THERAPEUTIC APPROACH IN THE EMERGENCY ROOM
}

Marcela B. Magalhães ${ }^{1}$; Eduardo A. Donadi² \& Paulo Louzada Jr²

1Pós-graduanda . Departamento de Clínica Médica. ${ }^{2}$ Docentes. Divisão de Imunologia Clínica. Departamento de Clínica Médica. Faculdade de Medicina de Ribeirão Preto - USP

Correspondência: Prof. Dr.Paulo Louzada Jr. Divisão de Imunologia Clínica. Departamento de Clínica Médica. Hospital das Clínicas da Faculdade de Medicina de Ribeirão Preto - USP. CEP 14049-900 Ribeirão Preto - SP. FAX: 16-633-6695 - E-mail: plouzada@fmrp.usp.br

MAGALHÃES MB; DONADI EA \& LOUZADA Jr P. Manifestações clínicas do lúpus eritematoso sistêmico: Abordagem diagnóstica e terapêutica na sala de urgência. Medicina, Ribeirão Preto, 36: 409-417, abr./dez. 2003.

RESUMO - O Lúpus Eritematoso Sistêmico (LES) é uma doença auto-imune, que cursa com variado conjunto de manifestações clínicas. Entre estas, algumas podem levar o paciente a procurar um serviço de urgência. É importante que o clínico geral saiba realizar a abordagem inicial do tipo de paciente, principalmente nos casos em que manifestações graves do LES constituem ameaça imediata à vida do doente. O objetivo desta revisão é discutir o diagnóstico clínico e laboratorial das manifestações dessa patologia,que exigem conduta de urgência. São descritas as formas graves de lesões cutâneas, renais, neuropsiquiátricas, gastrointestinais, pulmonares, cardíacas e hematológicas pelo LES. A terapêutica de tais manifestações é delineada a seguir, bem como todos os cuidados necessários no seguimento inicial. A abordagem do LES, na sala de urgência, apresenta-se como um dos maiores problemas pela dificuldade de diferenciação entre a atividade da doença e o quadro infeccioso subjacente. Descartar infecção é condição indispensável para que se possa iniciar o tratamento do LES, principalmente com medicação imunossupressora. Assim, não devem ser poupados esforços para se alcançar um diagnóstico acurado das manifestações do LES, na urgência, evitando-se erros de julgamento que possam ter conseqüências desastrosas.

UNITERMOS - Lúpus Eritematoso Sistêmico. Diagnóstico. Terapêutica. Urgência.

\section{1- INTRODUÇÃO}

O Lúpus Eritematoso Sistêmico (LES) é uma doença auto-imune, caracterizada pela produção de anticorpos contra componentes do núcleo celular, em associação com um variado conjunto de manifestações clínicas. A classificação diagnóstica do LES é realizada através da presença de quatro ou mais critérios, simultaneamente ou não, durante o intervalo de observação.

\section{CRITÉRIOS PARA CLASSIFICAÇÃO DIAGNÓSTICA DO LES}

1. Eritema malar: eritema fixo, plano ou elevado, sobre as eminências malares, tendendo a poupar sulco nasolabial.

2. Lúpus discóide: placas elevadas, eritematosas, com descamação ceratótica e crostículas; cicatrizes atróficas podem aparecer em lesões antigas.

3. Fotossensibilidade: eritema cutâneo, às vezes 
maculopapular, como resultado de uma exposição solar.

4. Úlceras orais: ulceração oral ou nasofaringeana, indolor, observada pelo médico.

5. Artrite: artrite não erosiva, envolvendo duas ou mais articulações periféricas.

6. Serosite : pleurite ou pericardite documentada por exames radiológicos.

7. Nefrite: proteinúria maior que $0,5 \mathrm{~g} / 24 \mathrm{~h}$, presente em 3 amostras, e/ou alterações no sedimento urinário (hematúria, cilindros granulosos).

8. Distúrbio neurológico: convulsões e psicose (descartando distúrbios metabólicos, infecção ou uso de medicações).

9. Alterações hematológicas: anemia hemolítica, auto-imune, com reticulocitose, ou Leucopenia: $\mathrm{GB}<4.000 \mathrm{cel} / \mathrm{mm} 3$, em 2 ou mais ocasiões, ou linfopenia: linfócitos < $1.500 \mathrm{cel} / \mathrm{mm} 3$, em 2 ou mais ocasiões ou trombocitopenia: plaquetas < $100.000 \mathrm{cel} / \mathrm{mm} 3$, na ausência de drogas desencadeadoras.

10. Alterações imunológicas: presença de anticorpos, como anticardiolipina, ou de anticorpos contra DNA nativo, ou de anticorpos contra antígeno nuclear Sm, ou teste para Lues falsamente positivo, confirmado com teste de fluorescência, com anticorpo contra o Treponema pallidum (FTAbs), negativo.

11. Fator antinuclear: títulos anormais de anticorpo antinuclear, por imunofluorescência ou teste equivalente, na ausência de utilização de drogas indutoras de LES.

\section{2- DIAGNÓSTICO E TERAPÊUTICA DAS MANIFESTAÇÕES CLÍNICAS DO LES NA UNIDADE DE EMERGÊNCIA}

$\mathrm{Na}$ Tabela I, estão diagramatizadas as manifestações clínicas e as respectivas terapêuticas, as comumente observadas no LES. A seguir, descreveremos, de forma resumida, tais manifestações e condutas.

\section{1- Cutâneas}

A ocorrência de lesões bolhosas, generalizadas pode representar uma urgência no manejo do LES. As erupções vesicobolhosas são disseminadas, predominando em face, pescoço e extremidades superiores. Elas podem aparecer em associação com a reativação da doença. O diagnóstico diferencial deve ser feito com pênfigo bolhoso, tardia porfiria cutânea, dermatite herpetiforme, epidermólise bolhosa e infecção. O diagnóstico é clínico e histopatológico (alterações histológicas semelhantes às da dermatite herpetiforme). $O$ tratamento com prednisona, $1 \mathrm{mg} / \mathrm{kg} / \mathrm{dia}$, muitas vezes, não é efetivo, bem como as lesões podem aparecer com o paciente já em uso de corticóides por outro envolvimento orgânico. Assim, a associação de difosfato de cloroquina $(250 \mathrm{mg} / \mathrm{d})$ e de imunossupressores (azatioprina 2-4mg/kg/dia, VO, ou pulso de ciclofosfamida, 0,5 a $1,0 \mathrm{~g} / \mathrm{m}^{2}$ de superfície corporal, mensal) deve ser estabelecida para o controle das lesões bolhosas.

\section{2- Renal}

Uma das manifestações comuns do LES, que exige tratamento de urgência é a glomerulonefrite proliferativa difusa, (classe IV da OMS). Ela se apresenta, clinicamente, por haver edema, hipertensão arterial e, ocasionalmente, uremia. Laboratorialmente, podemos encontrar proteinúria, em geral, maior que 1 $\mathrm{gr} / 24 \mathrm{~h}$, por vezes alcançando níveis nefróticos, cilindrúria (cilindros granulosos, hemáticos), hematúria, elevação de uréia e creatinina, alteração do perfil lipídico, complemento baixo e anti-DNA, nativo, positivo, em títulos elevados. Outra forma de apresentação da nefrite lúpica, na urgência, é a síndrome nefrótica pura, na maioria das vezes, ocorrendo em pacientes com glomerulonefrite membranosa (classe V). Todos os pacientes lúpicos, que apresentem manifestações sugestivas de nefrite devem ser submetidos à biópsia renal, se não houver contra-indicação. A justificativa para a realização de tal procedimento, não isenta de risco, é a possibilidade de dirigir a terapêutica conforme a classe da nefrite e de inferir o prognóstico renal do paciente através dos índice de cronicidade (no caso da glomerulonefrite proliferativa). O tratamento específico da glomerulonefrite proliferativa, difusa ou focal (classe III) é realizado com pulso de ciclofosfamida e de metilprednisolona. A glomerulonefrite mesangial (classe II) e a membranosa são tratadas, primariamente, com azatioprina, em nosso serviço, embora alguns centros optem por tratamento com corticóides ou conduta expectante no caso da primeira. Atualmente, temos dado preferência para o esquema de Ponticelli, modificado no tratamento da glomerulonefrite membranosa, que consiste na alternância mensal de ciclofosfamida VO (1-2 mg/kg/dia), com pulso de metilprednisolona ( $1 \mathrm{~g} / \mathrm{EV} / \mathrm{dia}$, por três dias). Inicia-se o primeiro mês com a ciclofosfamida e, no 
Tabela I: Manifestações clínicas do LES, mais comumente observadas na sala de urgência

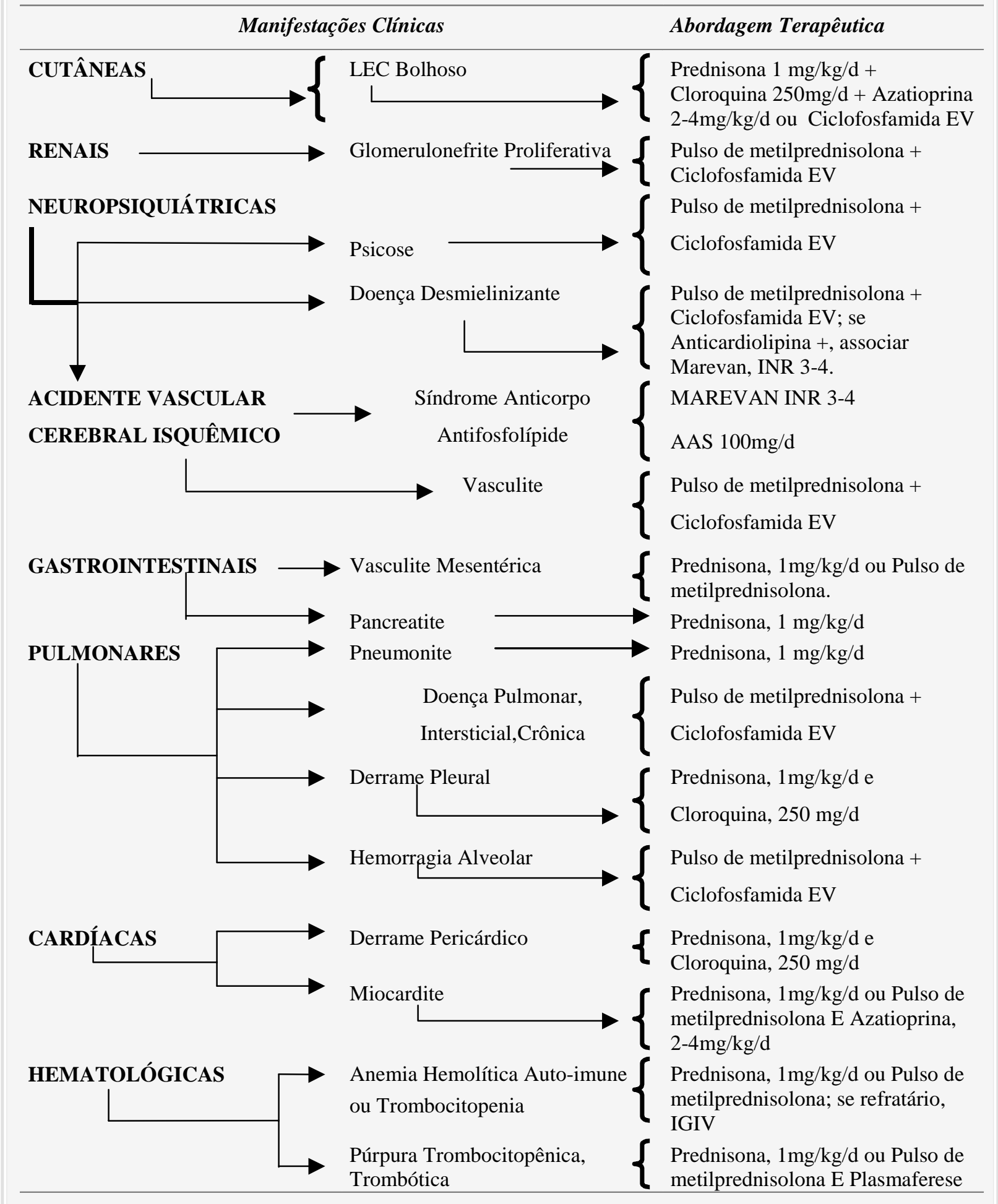

$30^{\circ}$ dia, realiza-se o pulso de metilprednisolona. Sempre o paciente fica recebendo uma dose baixa de prednisona $\mathrm{VO}$, nunca ultrapassando $10 \mathrm{mg} / \mathrm{dia}$. No $60^{\circ}$ dia, reinicia-se a ciclofosfamida VO, por mais 30 dias, alternando com o pulso, por um período de seis meses, quando o paciente é reavaliado em relação aos parâmetros de função renal e sedimentos urinários. Se houver resposta satisfatória, o tratamento é mantido por 
mais doze meses. A adoção de tal esquema foi feita devido à avaliação do tratamento de 180 pacientes com glomerulonefrite lúpica, durante o período de 1995 a 1999, em seguimento na Divisão de Imunologia Clínica do Hospital das Clínicas da Faculdade de Medicina de Ribeirão Preto, USP. Todos os pacientes foram submetidos à biópsia renal para a caracterização histológica da nefrite e a falência terapêutica foi estabelecida, quando o paciente ainda mantinha proteinúria de $24 \mathrm{~h}$ maior que $300 \mathrm{mg} /$ dia e elevação dos níveis de creatinina sérica ou diminuição do seu clearence em um valor maior que $15 \%$ dos seus valores basais. $\mathrm{Na}$ Tabela II, estão representados os tipos de glomerulonefrite e seus respectivos tratamentos, bem como a ocorrência ou não de remissão da atividade da nefrite. A partir desses resultados, a eficácia da azatioprina para o tratamento da glomerulonefrite membranosa foi revista, pois somente $64 \%$ dos pacientes obtiveram resposta. Por outro lado, o tratamento da glomerulonefrite proliferativa, focal, com componente membranoso, com a utilização de ciclofosfamida e metilprednisolona proporcionou um bom índice de remissão (vale ressaltar que o número de tratamentos foi de apenas 10 pacientes). Tais dados são semelhantes aos observados na literatura, quando se empregou a ciclofosfamida no tratamento de semelhante condição. Assim, o uso do esquema de Ponticelli, modificado passou a ser uma opção, quando não houver resposta satisfatória à azatioprina. Caso contrário, pode-se tentar ciclosporina microemulsificada $(2-5 \mathrm{mg} / \mathrm{kg} / \mathrm{dia})$, sempre com muita atenção em relação à deterioração da função renal e agravamento ou surgi-mento de hipertensão arterial, ambas, condições associadas ao uso da ciclosporina. Não temos experiência com o micofenolato de mofetil para o tratamento das glomerulonefrites lúpicas, apesar de relatos na literatura. $\mathrm{O}$ tratamento de suporte do doente com nefrite lúpica depende da manifestação clínica apresentada. Pacientes com hipertensão devem ser submetidos à restrição salina. A redução dos níveis pressóricos deve ser encarada como uma prioridade. A ingestão de gordura deve ser limitada para pacientes com hiperlipidemia, decorrente ou não de síndrome nefrótica. Pacientes com redução de mais de $40 \%$ da função renal devem ter a ingestão protéica controlada. Os diuréticos de alça (furosemide) podem ser utilizados para diminuição do edema, embora com cautela, em doentes apresentando creatinina maior que 3,0 . Salicilatos e antiinflamatórios não esteroidais devem ser evitados, já que podem agravar a lesão renal. A evolução do paciente e sua resposta ao tratamento podem ser avaliadas através da normalização de parâmetros clínicos e laboratoriais já citados, como sedimento urinário, níveis pressóricos e de creatinina, entre outros. Os cuidados para a administração dos pulsos de ciclofosfamida, endovenosa estão relatados no item 3.

Tabela II - Levantamento da distribuição das classes de glomerulonefrite lúpica durante o período de 1995 a 1999, classificadas segundo a Organização Mundial da Saúde ${ }^{1}$ em 180 pacientes com LES e seus respectivos tratamentos, bem como a eficácia terapêutica, após seis meses de medicação ${ }^{2}$

\begin{tabular}{|c|c|c|c|c|}
\hline Glomerulonefrite & Tratamento & $\begin{array}{c}\text { Total } \\
\mathrm{n}(\%)\end{array}$ & $\begin{array}{c}\text { Remissão Completa } \\
\mathrm{n}(\%)\end{array}$ & $\begin{array}{c}\text { Falência Ao Tratamento } \\
\mathrm{n}(\%)\end{array}$ \\
\hline CLASSE II & AZA $^{3}$ & $26(14 \%)$ & $21(80 \%)$ & $5(20 \%)$ \\
\hline CLASSE III & CYC4 + MP & $24(13 \%)$ & $20(83 \%)$ & $4(17 \%)$ \\
\hline CLASSE IV & CYC + MP & $94(52 \%)$ & $70(74 \%)$ & $24(26 \%)$ \\
\hline CLASSE V & AZA ou MP & $17(9 \%)$ & $11(64 \%)$ & $6(36 \%)$ \\
\hline CLASSE II e V & AZA & $9(5 \%)$ & $7(77 \%)$ & $2(23 \%)$ \\
\hline CLASSE III e V & CYC + MP & $10(6 \%)$ & $9(90 \%)$ & $1(10 \%)$ \\
\hline
\end{tabular}

${ }^{1}$ classe II: Glomerulonefrite mesangial; classe III: glomerulonefrite proliferativa, focal; classe IV: glomerulonefrite proliferativa, difusa; classe V: glomerulonefrite membranosa

${ }^{2}$ Louzada-Jr P et al., J Rheumatol 28: 46, 2001.

${ }^{3} \mathrm{AZA}=$ azatioprina, $\mathrm{VO}, 2-4 \mathrm{mg} / \mathrm{kg} / \mathrm{dia}$

${ }^{4} \mathrm{CYC}=$ ciclofosfamida $\mathrm{EV}, 0,5-1,0 \mathrm{~g} / \mathrm{m} 2$ superfície corporal, mensal

${ }^{5} \mathrm{MP}=$ metilprednisolona $\mathrm{EV}, 1 \mathrm{~g} / \mathrm{dia}$, durante três dias, mensal 


\section{3- Neuropsiquiátricas}

O paciente com LES pode evoluir com cerebrite, manifestada por convulsões, psicose e/ou estado confusional, agudo. O diagnóstico é eminentemente clínico, sendo importante excluir outras etiologias, como sepse, medicações e alterações metabólicas. Laboratorialmente, podemos encontrar anormalidades do líquor (proteína aumentada, glicose diminuída e pleocitose linfocitária), reação cruzada, autóloga para pesquisa de anticorpos linfocitotóxicos (auto-crossmatch), positiva no soro e/ou líquor e anticorpo anticardiolipina (ACA), positivo. A pesquisa de anticorpos antilinfocitotóxicos pelo método do auto-crossmatch pode ser positiva (tanto no líquor como no soro) em até $50 \%$ dos casos de manifestações neuropsiquiátricas, independente de ser a manifestação focal ou difusa. Apesar de sua positividade não ser tão elevada nos pacientes neuropsiquiátricos, sua presença no LES não neuropsiquiátrico é baixa (6\%), podendo fornecer subsídios para o diagnóstico de tal manifestação, no caso de ele ser positivo. Outros indícios de atividade do LES, acompanhando o quadro neurológico, são sugestivos, mas não diagnósticos, desse tipo de alteração. Quanto aos exames de imagem, podemos encontrar atrofia cortical à tomografia computadorizada (CT) de crânio e pequenos focos de aumento de sinal, dispersos pela substância branca e cinzenta, à ressonância nuclear magnética (RNM). O tratamento consiste em pulso de ciclofosfamida e metilprednisolona.

A doença desmielinizante, representada por mielite transversa ou esclerose lupóide, pode também ocorrer. Clinicamente, ela se apresenta com paraplegia ou tetraplegia, déficits sensoriais com nível sensitivo, perda de controle esfincteriano e, ocasionalmente, neuropatia craniana. Um achado laboratorial freqüente é o anticardiolipina (ACA) positivo. Observam-se áreas de desmielinização em encéfalo e/ou medula espinhal, na RNM. O tratamento é realizado com pulso de ciclofosfamida e metilprednisolona. Deve-se considerar, também, a utilização de pulso de imunoglobulina, endovenosa e plasmaferese. Realizar anticoagulação oral com warfarin (INR entre 3-4), se o ACA for positivo.

Acidentes cerebrovasculares podem ser causados por trombose (em associação com a síndrome do anticorpo antifosfolípide) e/ou vasculite. A principal alteração clínica é representada por déficits neurológicos, focais. Laboratorialmente, o anticardiolipina pode ser positivo (SAF) e o anticorpo anticitoplasma, de neutrófilos (ANCA) pode estar presente nos casos de vasculite de pequenos vasos (secundária ao LES ou mesmo à poliangeíte microscópica). Os exames de imagem mostram infartos cerebrais e a angiorressonância pode evidenciar vasculite. $\mathrm{O}$ tratamento consiste em anticoagulação (se ACA positivo) com warfarin, mantendo o INR entre 3,0-4,0 e/ou pulso de ciclofosfamida e metilprednisolona (se houver vasculite associada).

\section{4- Gastrointestinais}

As manifestações gastrointestinais são pouco comuns no LES. Pode ocorrer vasculite mesentérica, com presença de dor abdominal e, por vezes, enterorragia. Geralmente, está associada com envolvimento de outros órgãos. O quadro abdominal pode se manifestar como abdômen agudo, com peritonismo importante. A avaliação do cirurgião é mandatória e, por vezes, independente da intensidade da dor abdominal, o achado cirúrgico pode ser tanto de uma grande área de alças intestinais, necrosadas, como de simples aderência de alças, sem sinais de sofrimento isquêmico. Não há, ainda, nenhum exame subsidiário que permita diferenciar tal quadro. A arteriografia pode evidenciar vasculite, e a colonoscopia pode revelar ulcerações intestinais. O tratamento é feito com prednisona, $1 \mathrm{mg} /$ $\mathrm{kg} / \mathrm{dia}$, ou pulso de metilprednisolona, por 3 dias. Se houver suspeita de perfuração, é mandatória a realização de laparotomia. Outra manifestação gastrointestinal é a pancreatite secundária à vasculite pancreática. Porém, a pancreatite pode, também, ocorrer como complicação do uso prolongado e em altas doses de prednisona, bem como do uso de diuréticos tiazídicos e de azatioprina. Assim, o diagnóstico diferencial deve ser considerado antes de iniciada a terapia com corticóide. $\mathrm{O}$ tratamento da pancreatite lúpica é feito com prednisona, $1 \mathrm{mg} / \mathrm{kg} / \mathrm{dia}$.

\section{5- Pulmonares}

O paciente com LES pode evoluir com pneumonite. Existem duas formas de apresentação da manifestação pulmonar; a forma aguda (pneumonite), alveolar e a forma crônica (doença pulmonar, intersticial, crônica). A pneumonite assemelha-se a uma pneumonia, com dispnéia, tosse, febre, hemoptise e pleurisia. A radiografia de tórax mostra um infiltrado pulmonar, alveolar, com predomínio em bases, sendo que metade dos pacientes apresenta derrame pleural, associado. A pneumonite aguda não é uma manifes- 
tação comum no LES, representando menos de $10 \%$ do envolvimento, pulmonar. É imperativo descartar infecção associada,e o tratamento é feito com prednisona, $1 \mathrm{mg} / \mathrm{kg} / \mathrm{dia}$, ou pulso de metilprednisolona, por 3 dias. No caso de recorrência, a utilização de azatioprina, ou pulsos de ciclofosfamida, deve ser considerada. Essa manifestação aguda pode progredir para doença pulmonar crônica. A forma crônica (doença pulmonar intersticial crônica - DPIC) caracteriza-se por dispnéia progressiva, tosse seca, estertores pulmonares, basais (em velcro) e infiltrado pulmonar, intersticial, bibasal, na radiografia de tórax, melhor visualizado na tomografia computadorizada, de alta resolução. É indispensável descartar infecção. O lavado broncoalveolar pode mostrar celularidade com predomínio de neutrófilos (indicativo de lesão ativa). A espirometria tem padrão restritivo, com prejuízo na difusão de monóxido de carbono. O tratamento da DPIC é feito com pulsos de ciclofosfamida e metilprednisolona.

Outra manifestação pulmonar do LES é o derrame pleural. O paciente apresenta dor torácica, ventilatoriodependente, dispnéia, atrito pleural. A radiografia de tórax pode mostrar um derrame pleural, volumoso, ocasionalmente bilateral. No caso de dúvida quanto à sua etiologia, realizar toracocentese, para excluir infecção. A análise do líquido pleural demonstra: proteínas $>3 \mathrm{~g} / \mathrm{dl}$, total de glóbulos brancos entre 3.000 a 5.000 cels $/ \mathrm{ml}$, com predomínio de linfomononuclear, glicose próxima aos níveis séricos, diminuição do complemento, FAN positivo e $\mathrm{pH}>7,35$. O tratamento é realizado com prednisona, $1 \mathrm{mg} / \mathrm{kg} / \mathrm{dia}$, ou pulso de metilprednisolona, por 3 dias, e difosfato de cloroquina, $250 \mathrm{mg} / \mathrm{d}$ (efetivo como agente poupador de corticóides e para obtenção de resposta duradoura). Na literatura, é freqüentemente sugerido o uso de antiinflamatórios não esteroidais para controle de casos leves e moderados de pleurite e derrame pleural, reservando-se o esquema supracitado para casos mais graves ou refratários. Entretanto, a nossa experiência revela que a resposta a esse tipo de terapêutica raramente é satisfatória.

Uma manifestação pulmonar rara, porém freqüentemente fatal, é a hemorragia alveolar. O quadro clínico consiste em dispnéia, tosse, hemoptise, hipóxia, evoluindo para insuficiência respiratória, aguda e franca hemoptise. A rápida queda da hemoglobina e do hematócrito e o aparecimento de infiltrado alveolar, bilateral, geralmente difuso, caracteriza a hemorragia alveolar na sua fase de maior gravidade. Algumas vezes, a hemoptise pode não ser proeminente, retardando o diagnóstico. Neste caso, a queda rápida do hematócrito, em um paciente com LES, associada a um infiltrado alveolar, difuso, deve alertar o clínico sobre a possibilidade de hemorragia alveolar. É necessário excluir outras causas, como infecção, insuficiência cardíaca, congestiva, edema, agudo, de pulmão, não cardiogênico e coagulação intravascular, disseminada (CIVD). O tratamento é feito com pulso de ciclofosfamida e metilprednisolona. A associação com imunoglobulina endovenosa $(2 \mathrm{~g} / \mathrm{kg})$ e/ou plasmaferese pode ser útil.

\section{6- Cardíacas}

O paciente lúpico pode procurar uma unidade de emergência com quadro de pericardite ou mesmo com tamponamento cardíaco. O quadro clínico inclui dor torácica, atrito pericárdico, abafamento de bulhas, pulso paradoxal e estase jugular. Os três últimos sinais constituem evidência de tamponamento cardíaco em evolução. A radiografia de tórax mostra aumento de área cardíaca e o ecocardiograma evidencia espessamento pericárdico, derrame pericárdico, com ou sem sinais de tamponamento. $\mathrm{O}$ tratamento é realizado com prednisona $1 \mathrm{mg} / \mathrm{kg} / \mathrm{dia}$ ou pulso de metilprednisolona por 3 dias. Como já foi comentado com relação à pleurite, o tratamento com antiinflamatórios não esteroidais é recomendado na literatura para casos leves, mas raramente é efetivo.Há necessidade de punção pericárdica em caso de tamponamento cardíaco ou no caso de derrame pericárdico e febre, sem identificação do possível foco febril e a punção tornase necessária a fim de descartar pericardite infecciosa, cujos agentes mais comumente envolvidos são: Staphylococcus, Streptococcus e Mycobacterium Tuberculosis. A miocardite pode, também, ocorrer, com o paciente apresentando sintomas e sinais de insuficiência cardíaca, congestiva (ICC), taquicardia, sopros, ritmo em galope ou arritmias ventriculares. A radiografia de tórax mostra cardiomegalia, o eletrocardiograma pode evidenciar arritmias, defeitos de condução, e o ecocardiograma demonstra desempenho sistólico de ventrículo esquerdo, prejudicado, com alterações de mobilidade segmentar. O diagnóstico da miocardite lúpica, por vezes, é dificultado devido à presença de outros fatores que podem levar a ICC, tais como: uremia, hipertensão arterial não controlada, anemia, infecção sistêmica, doença valvar ou retenção de líquidos e de sal, resultante de doença renal ou do uso crônico de corticóides. O tratamento é realizado com prednisona $1 \mathrm{mg} / \mathrm{kg} /$ dia ou pulso de metilprednisolona por 3 dias, associado a azatioprina, 2-4mg/kg/dia. 


\section{7- Hematológicas}

A anemia hemolítica, auto-imune é uma das manifestações hematológicas do LES. O paciente pode apresentar, além da anemia, icterícia, esplenomegalia, cor anêmico. Laboratorialmente, ocorre anemia com reticulocitose, aumento de bilirrubinas, aumento de desidrogenase lática, Coombs positivo. $\mathrm{O}$ tratamento é feito com prednisona $1 \mathrm{mg} / \mathrm{kg} /$ dia ou pulso de metilprednisolona, por 3 dias. Nos casos refratários, o emprego da imunoglobulina intravenosa deve ser considerado. Outra manifestação hematológica é a plaquetopenia. O quadro clínico pode ser caracterizado por sangramentos de variadas origens, e o tratamento é realizado com prednisona $1 \mathrm{mg} / \mathrm{kg} / \mathrm{dia}$ ou pulso de metilprednisolona, por 3 dias. A imunoglobulina intravenosa pode, eventualmente, ser utilizada, com boa resposta, embora seus efeitos sejam freqüentemente pouco duradouros. Trata-se de medicação muito útil no caso de necessidade de cirurgia de urgência, como esplenectomia. Na literatura, não é considerada como terapêutica de primeira linha para plaquetopenia secundária ao LES. A púrpura trombocitopênica, trombótica (PTT) é uma complicação rara, porém grave do LES. Ela se caracteriza por febre, púrpura trombocitopênica, anemia hemolítica, microangiopática (presença de hemáceas fragmentadas - esquizócitos elevação da desidrogenase lática, reticulocitose, Coombs negativo, hiperbilirrubinemia indireta e hemoglobinúria), sintomas neurológicos, flutuantes e disfunção renal. $\mathrm{O}$ tratamento é realizado com prednisona $1 \mathrm{mg} / \mathrm{kg} / \mathrm{d}$ e plasmaferese.

\section{3- ORIENTAÇÕES PARA A PRESCRIÇÃO DAS DROGAS UTILIZADAS NA TERA- PÊUTICA DO LES, NA URGÊNCIA}

\section{1- Orientações gerais}

Sempre que possível, solicitar a avaliação de um especialista (imunologista clínico ou reumatologista) antes de iniciar a terapêutica imunossupressora, específica. O quadro clínico e os exames complementares do paciente devem ser cuidadosamente avaliados, pois, muitas vezes, a distinção entre as manifestações do LES e uma patologia infecciosa é um desafio diagnóstico. Erros de julgamento na definição do diagnóstico e da conduta podem ter graves conseqüências para tal tipo de doente, principalmente se considerarmos que a infecção é a principal causa de mor- te no LES. Entre as ferramentas disponíveis para a realização do diagnóstico diferencial, podemos citar as provas de atividade inflamatória. Embora a velocidade de hemossedimentação (VHS) encontre-se igualmente aumentada no LES em atividade (ou com anemia) e nos quadros infecciosos, o mesmo não pode ser dito quanto à proteína $\mathrm{C}$ reativa. Esta é, habitualmente, normal no LES, exceto nos quadros mais exuberantes de poliartrite ou serosite, mas encontra-se aumentada nos casos de infecção. O exame hematológico também fornece subsídios para a definição diagnóstica. O paciente com LES, geralmente, apresenta tendência para o desenvolvimento de leucopenia e linfopenia, de forma que um hemograma, mostrando leucocitose e desvio à esquerda, deve alertar para a possibilidade de infecção, ou de vasculite associada. A realização de culturas de fluidos corpóreos também é de grande utilidade e não deve ser dispensada, especialmente se o paciente estiver apresentando febre. Isto é válido para sangue, urina, fezes, líquido pleural, pericárdico ou sinovial, líquido cefalorraquidiano, lavado broncoalveolar, entre outros. Devem ser cultivados para germes piogênicos, aeróbios ou não, fungos e micobactérias. A pesquisa de parasitose intestinal deve ser sempre realizada nos pacientes candidatos à imunossupressão com agentes alquilantes. Antes da administração da ciclofosfamida, recomenda-se o tratamento de parasitoses intestinais, mesmo com parasitológico de fezes negativo, com albendazol, $400 \mathrm{mg}$, VO, por três dias, e metronidazol, $400 \mathrm{mg}$, VO, de $12 \mathrm{em} 12 \mathrm{~h}$, por cinco dias. O tratamento pode ser iniciado no mesmo dia da primeira dose de ciclofosfamida e repetido duas semanas após. No caso de infecção confirmada, somente realizar a ciclofosfamida após o tratamento ter sido completado. Os pacientes com LES, principalmente se estiverem sendo submetidos a tratamento imunossupressor, podem desenvolver infecções oportunistas. As efusões corpóreas, obtidas devem ser submetidas à análise citológica, além da realização de culturas. Finalmente, vale destacar o papel dos exames de imagem na diferenciação entre atividade do LES e infecção. Os exames mais simples e menos dispendiosos, como as radiografias, devem ser solicitados inicialmente. Na dúvida, entretanto, não se deve hesitar em recorrer a métodos mais sofisticados, como a ressonância nuclear, magnética. A prioridade deve ser sempre a realização do diagnóstico correto e a instituição da terapêutica adequada para o paciente. 


\section{2- Prednisona $1 \mathrm{mg} / \mathrm{kg} / \mathrm{dia}$}

Descartar infecção antes do início da medicação, pois tal dose de prednisona é imunossupressora . Cuidado na utilização em pacientes com diabetes Mellitus, hipertensão arterial sistêmica (HAS), glaucoma, insuficiência cardíaca congestiva (ICC) descompensada. (Vide secção seguinte). A medicação deve ser administrada em dose única, pela manhã, durante seis semanas. A partir da sexta semana deve ser iniciada a redução gradual do corticóide. Não suspender abruptamente a medicação. Na Tabela III, estão representados os principais efeitos antiinflamatórios e imunossupressores dos glicocorticóides.

\section{3- Pulso de metilprednisolona durante 3 dias}

Descartar infecção antes do início da medicação. Cuidado na utilização em pacientes com diabetes Mellitus, HAS, glaucoma, ICC descompensada, insuficiência renal. No caso dos diabéticos, realizar perfil glicêmico durante os 3 dias de tratamento, corrigindo a glicemia com insulina, se necessário. Durante a infusão da metilprednisolona, pode ocorrer retenção hidrossalina e agravar o quadro de hipertensão arterial. Assim, recomenda-se medir a pressão arterial de 15 em 15 min, durante a infusão. Pacientes com déficit de contractilidade miocárdica também devem ser observados com cautela, devido ao risco de edema agudo de pulmão. Pacientes com clearence de creatinina inferior a $30 \mathrm{ml} / \mathrm{min}$ somente devem ser subme- tidos a pulsoterapia com metilprednisolona, se possuírem via para realização de ultrafiltração de urgência. Podem ocorrer distúrbios de comportamento, como confusão mental, euforia, convulsões e, até mesmo, surto psicótico agudo. A ocorrência de arritmias cardíacas e morte súbita é rara. A preparação é feita diluindo-se $1,0 \mathrm{~g}$ de metilprednisolona em 250 a 500 $\mathrm{ml}$ de SG5\% (ou SF 0,9\%, se o paciente for diabético) e correr por via endovenosa em $2 \mathrm{~h}$, uma vez por dia, durante 3 dias consecutivos. Deixar uma dose de prednisona de manutenção (variável conforme o caso, mas sempre a menor possível, entre $10-15 \mathrm{mg} / \mathrm{dia}$ ), após o término do pulso.

\section{4- Pulso de ciclofosfamida e metilprednisolona}

Descartar infecção antes do início da medicação. Colher hemograma antes do pulso, pois existe restrição à realização do mesmo, em caso de leucopenia. Cuidado na utilização em pacientes com diabetes Mellitus, HAS, glaucoma, ICC descompensada, insuficiência renal. Tratamento antiparasitário antes do início da medicação. Administrar um antiemético de ação central (ondansetrona) antes do pulso. Calcular a dose de ciclofosfamida a ser administrada (20 a $30 \mathrm{mg} / \mathrm{kg}$ ) e diluir a mesma em $500 \mathrm{ml}$ de SG5\%. Acrescentar 1,0 g de metilprednisolona a tal solução e correr por via endovenosa em $2 \mathrm{~h}$. Hidratar o paciente com $500 \mathrm{ml}$ de SF $0,9 \%$, correndo em Y com a medicação. A hidratação é motivada pelo risco de cistite hemorrágica, como efeito colateral da ciclofosfa-

\section{Tabela III - Efeitos antiinflamatórios e imunossupressores dos glicocorticóides}

\section{EFEITOS ANTIINFLAMATÓRIOS}

Inibição da vasodilatação e da permeabilidade dos vasos sanguiíneos devido à diminuição da síntese do óxido nítrico. Inibição da migração de neutrófilos para a periferia levando à neutrofilia.

Inibição da síntese de mediadores inflamatórios como os eicosanóides pela inibição da fosfolipase A2 (via lipocortina) e da ciclooxigenase- 2

Inibição das colagenases

Alteração do equilibrio das citocinas em favor das citocinas antiinflamatórias (IL-10, TGF-B), enquanto que as citocinas pró-inflamatórias são inibidas (IL-1, TNF- $\alpha$ )

\section{EFEITOS IMUNOSSUPRESSORES}

Linfopenia (células T são mais afetadas que as B e as células T CD4 mais que as T CD8)

Inibição da ativação de células T

Inibição da síntese de IL-2

Inibição da apresentação antigênica pelo bloqueio da expressão de moléculas MHC de classe II)

Indução de apoptose de célula T 
mida. Pela mesma razão, deve-se administrar 1 ampola de furosemida após a infusão do pulso, visando estimular a diurese e diminuir o tempo de contato da acroleína (metabólito da ciclofosfamida) com a mucosa vesical. Em pacientes com diurese reduzida por qualquer razão, aplicar 1 ampola (400mg) de mesna, por via endovenosa, ao término do pulso, 4 e $8 \mathrm{~h}$ após o mesmo, também com o objetivo de evitar a cistite hemorrágica. Colher hemograma 14 dias após o pulso, para verificar se foi atingida a leucopenia desejada (3000-4000 leucócitos, sempre mantendo o número de neutrófilos acima de 1.500 cels $/ \mathrm{mm}^{3}$ ).

\section{5- Pulso de imunoglobulina humana endovenosa}

Cuidado na utilização em pacientes com HAS, insuficiência renal, ICC descompensada. A dose a ser utilizada é de $2,0 \mathrm{~g}$ por $\mathrm{kg}$ de peso por dia, dividida em 2 ou até 5 dias consecutivos. A medicação vem com diluente próprio ( 100 - $150 \mathrm{ml}$ por frasco). Realizar infusão lenta da droga, em concentração inferior a 5\% (5g/dl). Reações adversas, como cefaléia, dor torácica, dispnéia, lesões cutâneas, mal-estar, entre outras, podem ocorrer, e são controladas com a redução da velocidade ou com a suspensão da infusão.

MAGALHÃES MB; DONADI EA \& LOUZADA Jr P. Clinical manifestations of systemic lupus erythematosus: Diagnostic and therapeutic approach in the emergency room. Medicina, Ribeirão Preto, 36: 409-417, apr./dec. 2003.

ABSTRACT - Systemic Lupus Erythematosus (SLE) is an autoimmune disease with a diverse array of clinical manifestations. Some of them can bring the patient to urgency medical attention. It is important that the general clinician knows how to carry out the initial approach in this kind of patient, mainly in the cases with life-threatening manifestations of SLE. The purpose of this review is to discuss the manifestations of SLE that require urgency care. We describe severe forms of skin, renal, neuropsychiatry, gastrointestinal, pulmonary, cardiac and hematological involvements in SLE. The therapeutic aspects are described as well as the necessary care procedures in the initial follow-up of the patient. The principal difficulty of the management of SLE in the emergency room is differentiate disease activity from underlying infection. It is necessary to rule out infection before initiate immunosuppressive treatment. Thus, we should make an effort to obtain correct diagnosis of SLE manifestations in the emergency room, avoiding judgment mistakes that could be disastrous.

UNITERMS - Lupus Erythematosus, Systemic. Diagnosis. Therapeutic. Emergency.

\section{BIBLIOGRAFIA RECOMENDADA}

1 - KLIPPEL JH \& DIEPPE PA, eds. Rheumatology. $2^{\text {nd }}$. ed. Mosby, London, 1998.

2 - KOOPMAN WJ, ed. Arthritis and allied conditions. A textbook of rheumatology. $14^{\text {th. }}$. ed. Lea \& Febiger, Philadelphia, 2001.

3 - WALLACE DJ \& HAHN BH, eds. Dubois' Lupus erythematosus. $6^{\text {th }}$ ed. Williams, \& Wilkins, Baltimore, 2002.
4 - WARD MM. Hospital experience and mortality in patients with systemic lupus erythematosus. Atrthritis Rheum 42: 891898, 1999.

5 - WILLIANS FMK; CHINN S; HUGHES GRV \& LEACH RM. Critical illness in systemic lupus erythematosus and the antiphospholipid syndrome. Ann Rheum Dis 61: 414-421, 2002. 